\title{
PENGARUH KECEPATAN DAN KEDALAMAN POTONG PADA PROSES PEMBUBUTAN KONVENSIONAL TERHADAP KEKASARAN PERMUKAAN LUBANG
}

\author{
Bambang Siswanto ${ }^{1}$, Sunyoto ${ }^{2}$ \\ 1.2 Prodi Pendidikan Teknik Mesin, Universitas Negeri Semarang \\ Bambangsiswanto1910@gmail.com ${ }^{1}$,sunyoto@mail.unnes.ac.id ${ }^{2}$
}

\begin{abstract}
A good lathe process has good shape characteristics, precise size and small surface roughness. There are several factors that affect the roughness of the workpiece surface when doing turning process on the lathe, especially the use of cutting parameters. This study aims to determine the effect of cutting speed and depth of cut parameters on the roughness of cylinder block hole surface. This research is an experimental research using two independent variables, which are cutting speed and depth of cut. The dependent variable is surface roughness of cylinder block's hole. The research was done by making cast aluminum specimens and then turning a hole in the specimen with varied cutting speed and depth of cut. The surface roughness was then tested using Surfcorder SE 300. The obtained data were analyzed using descriptive analysis. Results show that there is an effect of cutting speed on the surface roughness of cylinder block, with the best result (smallest roughness value) was obtained from the use of cutting speed of $125 \mathrm{~m} / \mathrm{min}$. There is also an effect of depth of cut on the surface roughness of the cylinder block, with the best result given from the use of a $0.2 \mathrm{~mm}$ depth of cut.
\end{abstract}

Keywords: aluminum, cylinder block, cutting speed, depth of cut, hole surface roughness

\begin{abstract}
ABSTRAK
Ada beberapa faktor yang mempengaruhi tingkat kekasaran permukaan benda kerja pada proses pembubutan. Penelitian ini bertujuan untuk mengetahui pengaruh parameter kecepatan potong dan kedalaman potong terhadap kekasaran permukaan pada pembubutan lubang blok silinder mesin pemotong rumput. Penelitian ini merupakan penelitian eksperimen dengan variabel bebas kecepatan potong dan kedalaman potong, dan variabel terikat kekasaran permukaan lubang. Penelitian dilakukan dengan pembuatan spesimen dengan proses pengecoran aluminium kemudian spesimen dibubut lubang dengan diberi variasi kecepatan potong dan variasi kedalaman potong. Hasil pembubutan dilakukan uji kekasaran menggunakan Surfcorder SE 300. Data yang diperoleh kemudian dianalisis dengan analisis deskriptif. Hasil penelitian menunjukkan bahwa ada pengaruh kecepatan potong terhadap hasil kekasaran permukaan blok silinder mesin pemotong rumput, hasil paling baik dengan nilai kekasaran paling kecil diperoleh dari kecepatan potong $125 \mathrm{~m} /$ menit. Ada pengaruh kedalaman potong terhadap hasil kekasaran permukaan blok silinder mesin pemotong rumput, hasil paling baik dengan nilai kekasaran paling kecil diperoleh dari kedalaman potong 0,2 mm.
\end{abstract}

Kata Kunci: aluminium, blok silinder, kecepatan potong, kedalaman potong, kekasaran permukaan lubang.

\section{PENDAHULUAN}

Berbagai macam proses pembuatan dan pengerjaan produk blok silinder. Mulai dari pencetakan, pembentukan profil hingga finishing. Dalam pembentukan blok silinder dapat menggunakan cara kolter dan dapat juga dengan proses pembubutan. Dibutuhkan kepresisian yang tinggi dalam pengerjaan lubang silinder karena nantinya sebagai tempat piston bekerja. Proses pembubutan menjadi salah satu proses pengerjaan blok silinder terutama dalam pembuatan lubang silinder.

Sumbodo (2008:227), menjelaskan bahwa prinsip kerja proses pembubutan adalah memutar benda kerja dan menggunakan mata pahat untuk memotong atau menyayat benda kerja tersebut. Widarto (2008: 155) menyatakan bahwa langkah kerja dalam proses bubut meliputi: 1) persiapan bahan benda kerja; 2) setting mesin; 3) pemasangan pahat; 4) 
penentuan jenis pemotongan (bubut lurus, permukaan, profil, alur, ulir); 5) penentuan kondisi pemotongan; 6) perhitungan waktu pemotongan, dan 7) pemeriksaan hasil berdasarkan gambar kerja. Mesin bubut merupakan salah satu mesin produksi yang dipakai untuk membentuk benda kerja yang berbentuk silindris. Mesin bubut dibagi menjadi dua tipe yaitu CNC dan bubut konvensional. Mesin bubut CNC adalah mesin bubut semi otomatis yang bergerak dengan motor penggerak yang dijalankan oleh program komputer. Bubut CNC memiliki tingkat akurasi yang cukup tinggi serta mudah dalam pengerjaan dalam jumlah banyak. Namun untuk harga dan biaya perawatan cukup tinggi sehingga banyak industri menengah ke bawah yang memilih menggunakan mesin bubut konvensional.

Hasil proses pembubutan yang baik memiliki karakteristik bentuk yang baik, ukuran yang presisi serta kekasaran permukaan yang nilainya kecil (Gupta, Gupta \& Mittal, 2009: 91). Untuk menghasilkan buring yang baik harus memiliki lubang silinder dengan nilai kekasaran kecil, karena lubang silinder tersebut nantinya akan terjadi proses gesekan antara cincin piston dengan dinding silinder. Diperlukan ukuran yang presisi agar tidak terjadi kebocoran ketika proses pembakaran. Apabila buring memiliki karakteristik tersebut, maka motor bakar akan dapat bekerja secara optimal dan minim kerusakan, sehingga memiliki umur pakai yang tinggi.

Putra (2016), menjelaskan bahwa ada beberapa faktor yang mempengaruhi kekasaran permukaan benda kerja saat melakukan proses pembubutan. Selain dari faktor skill operator yang berpengaruh, kedalaman pemotongan dan kecepatan pemotongan juga sangat berpengaruh terhadap kekasaran permukaan benda kerja. Sebagaimana yang diutarakan Helmi \& Hassan (2008: 60) bahwa kualitas pembubutan ditentukan selain kecepatan putar dan gerak makan juga kedalaman potong. Kedalaman pemotongan sering diabaikan oleh operator karena ingin cepat selesai dalam pengerjaan biasanya sering menggunakan kedalaman pemotongan yang ukurannya tinggi. Sedangkan kecepatan potong juga sering diabaikan karena faktor waktu agar pengerjaan cepat selesai. Padahal kedua faktor tersebut sangatlah penting dalam proses pembubutan untuk memperoleh hasil permukaan yang sesuai serta tinggat kekasaran yang kecil Geirling (1965: 25).

Penelitian ini bertujuan untuk mengetahui pengaruh beberapa parameter pemotongan pada proses pembubutan lubang terhadap kekasaran permukaan lubang blok silinder mesin pemotong rumput, yang berfokus pada kecepatan potong dan kedalaman potong.

\section{METODE}

Penelitian ini merupakan penelitian eksperimen. Sugiyono (2015:14), menjelaskan bahwa penelitian eksperimen adalah penelitian yang digunakan untuk mencari pengaruh perlakuan tertentu terhadap yang lain dalam kondisi yang terkendalikan. Pada penelitian ini menggunakan desain eksperimen faktorial. Variabel bebas pada penelitian ini adalah kecepatan potong (93 m/menit dan $125 \mathrm{~m} /$ menit) dan kedalaman potong $(0,2 \mathrm{~mm}$ dan $0,5 \mathrm{~mm})$. Variabel terikat pada penelitian ini adalah kekasaran permukaan blok silinder mesin pemotong rumput. Data uji kekasaran dimasukkan kedalam tabel yang nanti hasilnya akan diolah menjadi bentuk deskriptif.

Alat penelitian berupa: 1) Tungku Pelebur, 2) Pasir Cetakan, 3) Rangka Cetak, 4) Pola, 5) Core, 6) Mesin Bubut Konvensional, 7) Jangka Sorong, dan 7) Surface Roughness. Sedangkan bahan penelitian adalah berupa blok silinder hasil peleburan berbahan dasar Aluminium. Diagram alir proses penelitian sebagaimana ditunjukkan pada Gambar 1.

\section{HASIL DAN PEMBAHASAN}

Proses pembubutan dengan menggunakan parameter pemotongan yang ditentukan maka dilakukan uji kekasaran. Hal ini untuk mengetahui tingkat kekasaran hasil pembubutan pada blok silinder tersebut. Instrumen data hasil 
dimasukkan ke dalam Tabel Ekserimen Faktorial untuk memperoleh rata-rata kekasaran sebagaimana ditunjukkan pada Tabel 1.

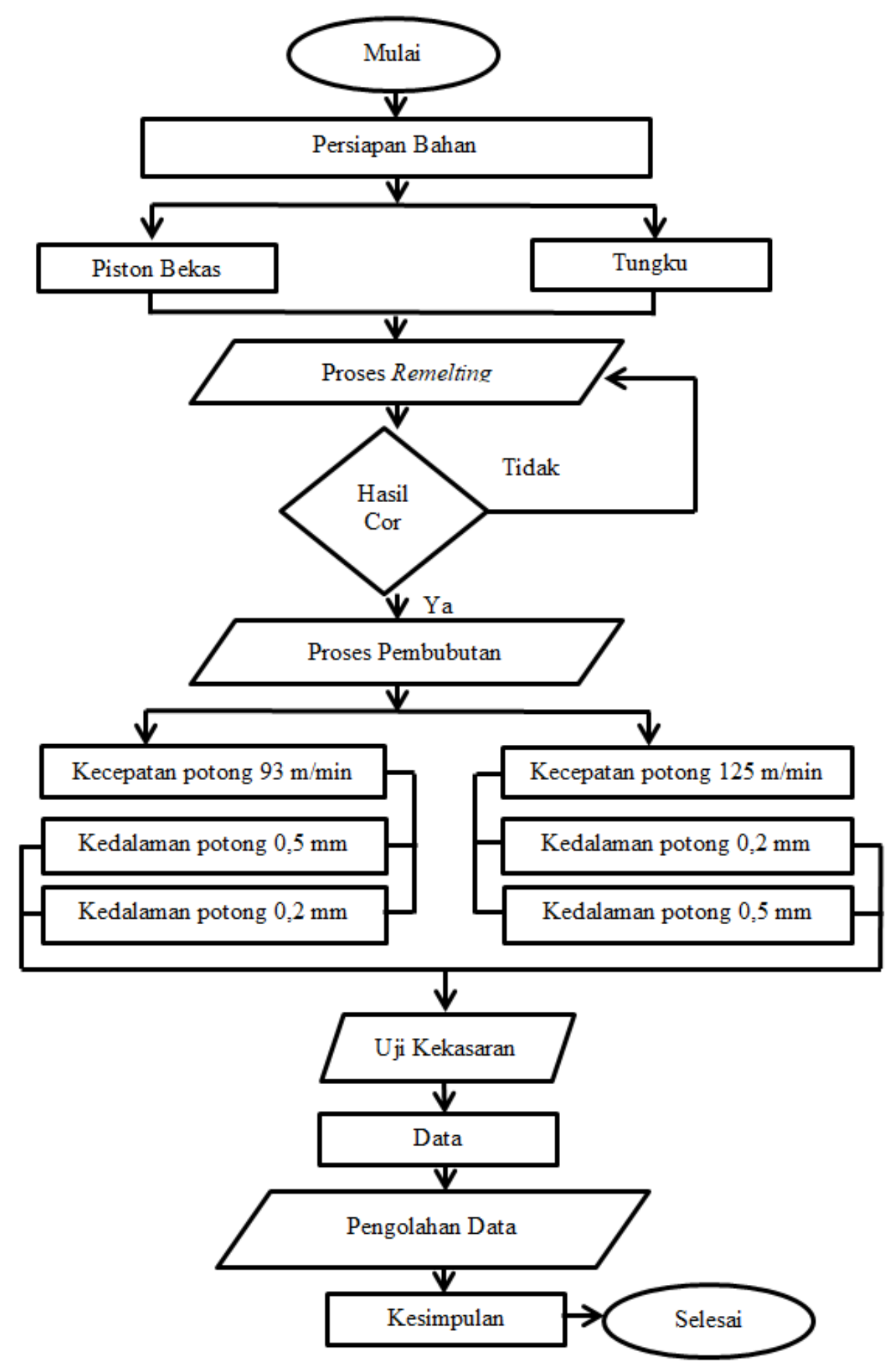

Gambar 1. Diagram Alir Proses Penelitian. 
Dari data hasil pengukuran dan perhitungan ratarata nilai kekasaran pada Tabel 1. di atas selanjutnya diubah dalam bentuk grafik untuk memperjelas pengaruh kekasaran dari masingmasing variabel, sebagaimana ditunjukkan pada Gambar 2.

Tabel 1. Data Eksperimen Faktorial Kecepatan Pemotongan dan Kedalaman Pemotongan.

\begin{tabular}{|c|c|c|c|c|c|}
\hline \multirow{2}{*}{\multicolumn{2}{|c|}{ Taraf }} & \multicolumn{2}{|c|}{$\begin{array}{c}\text { Faktor Kecepatan } \\
\text { Potong } \\
\end{array}$} & \multirow{2}{*}{\multicolumn{2}{|c|}{ Rata-rata }} \\
\hline & & $\begin{array}{c}93 \\
\mathrm{~m} / \mathrm{min}\end{array}$ & $\begin{array}{c}125 \\
\mathrm{~m} / \mathrm{min}\end{array}$ & & ata \\
\hline \multirow{10}{*}{ 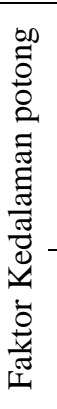 } & & 10,106 & 4,336 & \multirow{6}{*}{$\begin{array}{c}9,457 \\
\mu m\end{array}$} & \multirow{6}{*}{$\begin{array}{c}4,875 \\
\mu m\end{array}$} \\
\hline & 0 , & $\mu m$ & $\mu m$ & & \\
\hline & 2 & 8,217 & 4,649 & & \\
\hline & $\mathrm{m}$ & $\mu m$ & $\mu m$ & & \\
\hline & $\mathrm{m}$ & 10,050 & 5,637 & & \\
\hline & & $\mu m$ & $\mu m$ & & \\
\hline & 0 , & 10,890 & 9,345 & & \\
\hline & 5 & $\mu m$ & $\mu m$ & 10,349 & 9,125 \\
\hline & $\mathrm{m}$ & 8,682 & 10,808 & $\mu m$ & $\mu m$ \\
\hline & $\mathrm{m}$ & $\mu m$ & $\mu m$ & & \\
\hline
\end{tabular}

\begin{tabular}{cc}
\hline 11,475 & 7,221 \\
$\mu m$ & $\mu m$ \\
\hline Hasil pengukuran rata-rata dalam Tabel 1
\end{tabular}
dan grafik Gambar 2 memperlihatkan bahwa kecepatan potong untuk proses pengerjaan penyelesaian menghasilkan Ra yang berbeda. Pada kecepatan potong $93 \mathrm{~m} / \mathrm{menit}$ menghasilkan rata-rata Ra yang lebih besar dari pada rata-rata $\mathrm{Ra}$ pada kecepatan potong 125 m/menit, dengan kata lain kecepatan potong 125 $\mathrm{m} /$ menit menghasilkan rata-rata Ra lebih rendah. Hal ini sesuai dengan penelitian sebelumnya yaitu semakin rendah kedalaman potong maka semakin rendah nilai kekasarannya (Tschatsch, 2009: 30) . Untuk hasil perbandingan tabel kecepatan potong proses pengerjaan penyelesaian pada buku dihasilkan bahwa untuk nilai kekasaran rendah yang dihasilkan untuk kecepatan potong aluminium tidak hanya sampai di 93 m/menit, namun dapat sampai 125 m/menit

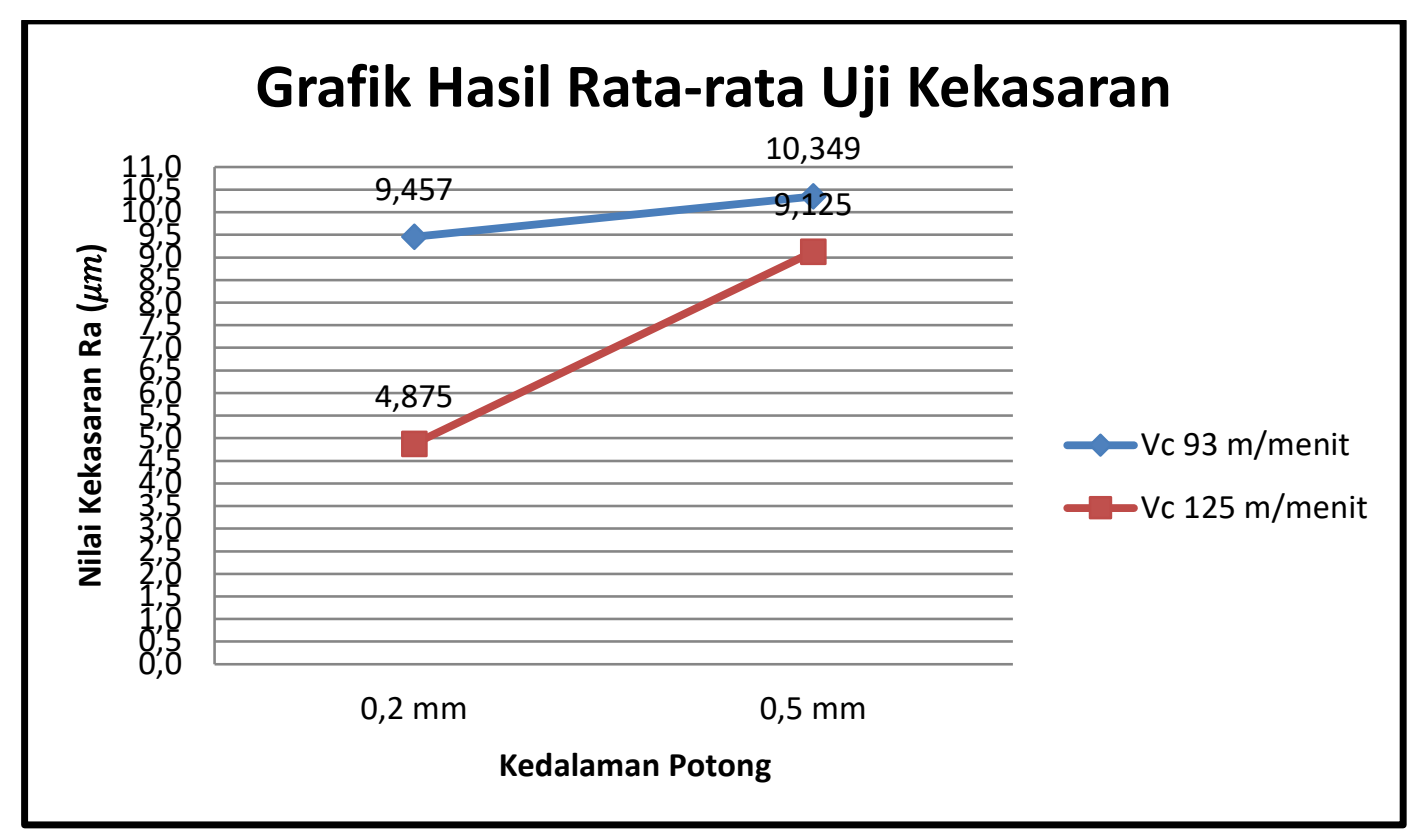

Gambar 2. Grafik Hasil Rata-rata Uji Kekasaran.

\section{SIMPULAN}

Berdasarkan penyajian data dan pembahasan di atas maka dapat disimpulkan bahwa: 1) Ada pengaruh kecepatan potong terhadap hasil kekasaran permukaan lubang blok silinder mesin pemotong rumput. Hasil paling baik dengan nilai kekasaran paling kecil diperoleh dari kecepatan potong $125 \mathrm{~m} /$ menit, dan 2) Ada pengaruh kedalaman potong terhadap hasil kekasaran permukaan lubang blok silinder mesin pemotong rumput. Hasil paling baik dengan nilai kekasaran paling kecil diperoleh dari kedalaman potong 0,2 mm. 
Beberapa hal ini sebagai saran yaitu: a) setelah mengetahui pengaruh variasi kecepatan potong dengan kedalaman potong pada proses pembubutan lubang blok silinder mesin pemotong rumput sebaiknya kecepatan potong dan kedalaman potong yang hasilnya paling baik dapat digunakan sebagai acuan untuk membubut lubang, b) untuk peneliti maupun mahasiswa yang akan meneliti proses pembubutan lubang maka penelitian ini dapat dijadikan sebagai acuan atau referensi teoritis, c) pada kegiatan praktikum di lapangan sebaiknya memperhatikan hasil penelitian ini sebagai acuan atau referensi praktis dalam proses pembubutan lubang bahan aluminium, dan d) dengan penelitian ini maka Teknik Mesin UNNES sudah mampu membuat blok silinder mesin pemotong rumput sendiri, kedepannya harapannya dapat diproduksi secara masal dengan desain yang lebih simpel dan tidak memakan banyak biaya.

\section{DAFTAR RUJUKAN}

Geirling, H. (1977). All about machine tools. New Delhi: Wiley Eastern Limited.

Gupta, H.N., Gupta, R.C., \& Mittal, A. (2009). Manufacturing processes $\left(2^{\text {nd }}\right.$ ed.) New Delhi: New Age International.

Helmi, Y.A. \& Hassan, E.H. (2008). Machining technology: Machine tools and operations. London: CRC Press.

Putra, I. E., \& Adil, R. (2016). Pengaruh Kecepatan Asutan Dan Kedalaman Potong Terhadap Kekasaran Permukaan Aluminium Pada Bubut Cnc Tu2a. Jurnal Momentum, 18(1).

Sugiyono. 2015. Metode Penelitian pendidikan: Pendekatan Kuantitatif, Kualitatif, dan $R \& D$. Bandung: Alfabeta.

Sumbodo, Wirawan. 2008. Teknik Produksi Mesin Indrustri Jilid 2. Jakarta: Direktorat Pembinaan Sekolah Menengah Kejuruan.

Tschatsch, H. (2009). Applied machining technology. Dresden: Springer.

Widarto. (2008). Teknik pemesinan jilid 1 \& 2. Jakarta: Depdiknas 